\title{
California report pinpoints hazards in layout of Three Mile Island control room
}

IN early May, California's governor Edmund G. Brown Jr called for a national moratorium on construction of nuclear power plants and declared himself to be "at the forefront of the antinuclear movement". Some political observers have suggested that his actions represent a new expression of his presidential ambitions, but the governor also seems to be taking seriously a report prepared by his staff that condemns the state of "human factors engineering' in the nuclear industry. In a letter to Nuclear Regulatory Commission (NRC) chairman Joseph M. Hendrie, Brown wrote: "I am informed that the design of nuclear power plant control rooms may represent a significant safety hazard".

A copy of this staff report, together with some of the supporting documentation, has become available to Nature. The report was prepared by Wilson Clark, Assistant to the Governor for Issues and Planning, and three assistants, two of whom have experience in nuclear engineering. It concludes that many nuclear power plants "are poorly instrumented and designed for adequate reactor operator control ... Modern nuclear technology is harnessed by antiquated control technology which represents a clear and present hazard."

Clark summarised the report's conclusions in a letter to the chairman of the Presidential Commission on the Accident at Three Mile Island, John G. Kemeny. He cited the NRC's preliminary evaluation of the Three Mile Island accident as a vindication of his belief that poor design for human operation were "a leading, if not the leading factor, in the near-disaster at Three Mile Island." He catalogued three main hazards covered in his report that bear on Three Mile Island:

- poor layout, making plant operation difficult and dangerous;

- inadequate display of control room information; and

- confusing and incomplete operational procedures which lengthen operator responses, decreasing reliability.

Clark's point has been made before, but the issue generated little interest until the series of interrelated human and instrumentation errors at Three Mile Island. The famous Reactor Safety Study, WASH-1400, which gave the nuclear industry a generally clean bill of health, criticised the design of controls and displays and their arrangement on operator panels. Later, a task force of the Electric Power Research Institute (EPRI) expressed similar criticism and recommended that EPRI review the problem. The review was conducted by the Lockheed Missiles and Space Company and published in late 1976. Although the conclusions of the Lockheed/EPRI report were generally low key, the illustrations were devastating. With such understatements as "the study findings paint a rather negative picture" the report catalogues a substantial list of design faults that could directly affect an operator's ability to react quickly in an emergency. These include:

- massive arrays of identical control/ display units with no clearly identified subpanel grouping;

- control levers so large that individual control panels expand to enormous size;

- separation of related panels into two areas so that two operators are required to coordinate their actions even when separated by as much as 50 feet; and

- placement of gauges so high that an operator cannot read them without standing on a footstool, or on a wall opposite the location of related control levers.

Even such a simple matter as the number, placement and ease of replacing signal lamps can have serious consequences. The Lockheed/EPRI study found that "indicator reliability is a problem and there are a surprising number of burned-out, single lamp indicators at any given time" in the reactors surveyed. Warning lights are so numerous that many operators become cavalier about 'nuisance alarms'. And to replace burned-out lamps operators sometimes stand precariously on a control panel.

The Clark, report shows how prophetic this passage of the 1976 study was to be. In March 1978, an operator dropped a light bulb into an open con- trol panel at California's Rancho Seco plant, while trying to fix a burned out indicator. The resulting short circuit caused the reactor to shut down, knocked out two-thirds of its temperature, pressure, flow and level signals, and cut off auxiliary feedwater for seven minutes. Clark concludes: "Had other safety systems not performed adequately, this transient could have been similar to the accident at Three Mile Island, which experienced a loss of auxiliary feedwater cooling for only eight minutes."

Governor Brown's team also cited a study of the Zion nuclear power plant by Alan Swain in 1975, for the NRC. According to the Clark report, the owner of the Zion plant had been able to suppress distribution of the document, which had found in a 'talkthrough' of procedures to use in a serious accident, that "even experienced operators had some difficulty in locating particular controls and displays."

It remains to be seen what action will be taken to improve the confusing array of instruments, dials and switches facing reactor operators, but the NRC has at least acknowledged the problem. A recent staff report on reactors designed by Babcock and Wilcox (who designed the plant at Three Mile Island) states: "Human factors engineering has not been sufficiently emphasised in the design and layout of the control rooms. The location of instruments and controls in many power plants often increases the likelihood of operator error or, at the least, impedes the operator in efficientiy carrying out the normal, abnormal, and emergency actions required of him."

John Douglas

\section{US to study health effects of accident}

ThE US Department of Health, Education and Welfare announced last week that it is to carry out a number of surveys of the possible health effects on those who were exposed to radiation as a result of the nuclear accident two months ago at the Three Mile Island nuclear power plant in Pennsylvania.

One survey will cover pregnant women living within 10 miles of the plant, who will receive regular health checks throughout their pregnancy. Their children will be monitored for the first few months after birth. The National Institute of Mental Health will carry out a survey of a representative group of people "subject to the strain of the accident", and a further study will examine the health of the workers at the plant.

In addition there will be a general survey of the health of 50,000 residents living within five miles of the plant. "It's just common sense to do this. There is no reason for alarm. I said some time ago that we would study the population, and that we would particular focus on pregnant women", Health Secretary Joseph Califano said last week. The survey will be financed by the Center for Disease Control and the National Cancer Institute. State officials hope to continue the study on a year-to-year basis for up to 20 years.

David Dickson 